ISSN: 2715-6273 (online) 2714-6510 (print) https://jurnalfuad.org/index.php/ishlah/index

\title{
Pengaruh Seni Arsitektur Terhadap Perkembangan Pendidikan Islam di Andalusia
}

\author{
Nurul Hidayati, Yazida Ichsan, Ratna Wulandari, Dwi Aknan Lutfiyan \\ Fakultas Agama Islam Universitas Ahmad Dahlan Yogyakarta \\ Dosen Fakultas Agama Islam Universitas Ahmad Dahlan Yogyakarta \\ Fakultas Agama Islam Universitas Ahmad Dahlan Yogyakarta \\ Fakultas Agama Islam Universitas Ahmad Dahlan Yogyakarta \\ nurul1800331026@webmail.uad.ac.id
}

\begin{abstract}
The discourse related to the influence of architecture on the development of Islamic education in Andalusia is actually a very important discussion to do. On the one hand, from a historical perspective, under the Umayyah II dynasty, Andalusia became a beacon of civilization in the fields of science, technology and art that contributed to Europe. On the other hand, art as part of the manifestation of civilization is rarely studied, especially its influence on Islamic education. The purpose of this research is to know and describe how the development of architectural arts and its effects on Islamic education. The purpose of this research is to identify and describe how the development of architectural arts and its effects on Islamic education. This research is a historical research which is carried out in several steps: heuristics, criticism, interpretation and historiography. The results showed that the triumph of Islam in Andalusia left a special space in the representation of Western civilization even today. Various historical relics have had their own influence on culture and culture in Spain, especially Islamic architectural arts. Mosques, palaces, forts, tombs, and secular buildings in Spain are heavily influenced by Islamic culture. Apart from being a legacy of Islamic culture, the art of architecture in Andalusia has a strong influence on the development of Islamic education in modern-day Spain. Especially in the development of Islamic education, architectural art has a strategic position in its influence. This can be seen in the calligraphic patterns in mosques and other important places in Andalusia that use pieces of the Al-Qur'an verses as their motifs. This verse piece is not only an ornament but aims to introduce Islam to the community and as proof that Islam had an influence in Andalusia.
\end{abstract}

Keywords: Architectural Art, Andalusia, Islamic Education

Abstrak. Diskursus berkaitan dengan pengaruh arsitektur terhadap perkembangan pendidikan Islam di Andalusia sesungguhnya menjadi pembahasan yang sangat penting untuk dilakukan. Disatu sisi, dalam perspektif sejarah, di bawah Dinasti Umayyah II, Andalusia menjadi mercusuar peradaban baik dalam bidang ilmu pengetahuan, teknologi dan seni yang memiliki kontribusi terhadap Eropa. Disisi lain, seni sebagai bagian dari manifestasi peradaban sangat jarang dikaji, khususnya pengaruhnya terhadap pendidikan Islam. Tujuan dari penelitian ini adalah mengetahui dan menggambarkan bagaimana perkembangan seni arsitektur dan pengaruhnya terhadap pendidikan Islam. Penelitian ini merupakan penelitian sejarah yang dilakukan melalui beberapa langkah: heuristik, kritik, interpretasi dan historiografi. Hasil penelitian menunjukkan bahwa kejayaan Islam di Andalusia menyisakan ruang khusus dalam representasi peradaban Barat bahkan hingga masa 
kini. Berbagai peninggalan sejarah memberikan pengaruh tersendiri bagi kultur dan budaya di Spanyol, khususnya seni arsitektur Islam. Masjid, istana, benteng, makam, hingga bangunan sekuler di Spanyol banyak dipengaruhi oleh kebudayaan Islam. Selain sebagai peninggalan budaya Islam, seni arsitektur di Andalusia memberikan pengaruh yang kuat terhadap perkembangan pendidikan Islam di Spanyol masa kini. Khususnya dalam perkembangan pendidikan Islam, seni arsitektur memiliki posisi strategis dalam pengaruhnya. Hal ini dapat terlihat pada pola kaligrafi yang ada di masjid dan tempat-tempat penting di Andalusia yang menggunakan potongan ayat Al-Qur'an sebagai motifnya. Potongan ayat ini tidak hanya sebagai ornamen namun bertujuan mengenalkan Islam kepada masyarakat dan sebagai bukti bahwa Islam pernah memberikan pengaruh di Andalusia.

Kata kunci: Seni arsitektur, Andalusia, Pendidikan Islam

\section{PENDAHULUAN}

Diskursus berkaitan dengan Andalusia tidak dapat terlepas dari perspektif historis masa kejayaan Islam di Eropa yang memberikan kontribusi bagi renaissance Eropa. Kemajuan Andalusia sendiri tidaklah singkat, melainkan melalui pergumulan yang sangat panjang. Diawali dengan penaklukan bangsa Romawi terhadap penduduk asli yang dikenal dengan bangsa Iberia (Las Iberes), kemudian berpindah tangan dibawah kekuasaan Bangsa Visigothic yang berasal dari Jerman, Andalusia mengalami stagnasi dalam bidang peradaban dan hampir seluruh wilayah Spanyol mengalami penderitaan secara fisik maupun psikis (Ichsan, 2020).

Keadaan tersebut, bertolak belakang dengan kondisi Spanyol dibawah kekuasaan Islam. Kebijakan Musa bin Nushair mengutus Tharif bin Malik tahun $710 \mathrm{M}$ dengan bantuan kapal Julian, membuka gerbang bagi penaklukan di wilayah Eropa bagian selatan. Hal tersebut ditindaklanjuti dengan pengiriman 7000 pasukan dibawah komando Thariq bin Ziyad melalui selat Gibraltar (Jabal Thariq) dapat menguasai hampir seluruh wilayah Spanyol dan menaklukkan Roderick penguasa terakhir bangsa Visihothic (Ahmad Syalabi, 2003). Selama tujuh abad, diawali dengan kepemimpinan wali di bawah Umayyah Damaskus, kepemimpinan amir, khalifah, Muluk Thawaif, dinasti Murabithun, dan dinasti bani Ahmar, Andalusia menjelma 
menjadi mercusuar baik dalam bidang ilmu pengetahuan maupun peradaban (Badri Yatim, 2006).

Pada bidang ilmu pengetahuan dan pemikiran, lahirlah pemikiran mistis. iluminis, rasionalis dan dogmatis (Abu Muhammad Iqbal, 2015) pada masa ini lahirlah tokoh sekaliber Ibnu Bajjah, Ibnu Thufail, Ibnu Rusyd, Ibnu Hazm, Ibnu 'Arabi . Adapun dalam bidang peradaban, Andalusia representasi bagi kemajuan peradaban. Dalam bidang pembangunan, Andalusia memiliki 3.837 masjid dilengkapi dengan berbagai fasilitas umum seperti jalan, pasar, tempat pemandian, rumah penduduk, dan pertokoan. Untuk meningkatkan perekonomian, pemerintah membangun jembatan, irigasi, dam, pabrik logam, tembikar, tekstil, kayu dan kulit. Selain itu, didirikan pula pabrik tepung, gelas, gading sebagai perabot mimbar dan pintu masjid dan minyak (Salleh et al., 2018).

Selain itu, manifestasi peradaban Andalusia tercermin pada bidang seni seperti seni musik dengan lahirnya not lagu do, re, mi, fa so, la, si, do (Suyuthi Pulungan, 2019). Selain itu terdapat pula seni arsitek seperti kubah yang membutuhkan perhitungan yang sangat rumit, seni tiang, ornamen timbul, jendela rumah, seni taqniyah Ash Shautiyyat Al-Mi'mariyah, bendungan, jembatan dan lain sebagainya (Raghib As-Sirjani, 2012).

Seni merupakan sisa-sisa peninggalan terbanyak yang masih bisa ditemukan di Andalusia. Khususnya seni arsitektur berupa ukiran pada masjid, benteng, hingga gedung pemerintahan yang bergaya Islam dengan motif yang dipenuhi potongan ayat-ayat Al-Qur'an dan dihiasi motif alam seperti dedaunan dan bunga. Berbagai peninggalan tersebut menjadi saksi sejarah bagi perkembangan Andalusia pada abad pertengahan yang sampai saat ini masih tetap eksis yang dapat dijadikan sebagai motivator, inisiator bagi kemajuan Islam saat ini.

Dewasa ini, diskursus berkaitan dengan seni seharusnya tidak hanya ditinjau dari perspektif hukum Islam, melainkan juga perlu dilihat dari 
perspektif pendidikan Islam dimana sejarah merupakan bagian yang melekat dan tidak terpisahkan dari pendidikan Islam. Sebagaimana pernyataan H.A.R Gibb yang menyatakan bahwa Agama Islam bukanlah sekedar sistem teologi, melainkan agama yang memiliki peradaban yang sangat sempurna (Sumirah, 2020). Permasalahan yang terjadi, dalam pendidikan Islam, seni arsitektur sangat jarang menjadi pembahasan utama maupun sub bab tertentu. Penelitian ini memiliki beberapa fokus tujuan. Pertama, mengenalkan seni arsitektur sebagai bagian dari peradaban Islam, khususnya Andalusia. Kedua, menekankan pada pendidikan Islam bahwa seni tidak hanya ditinjau dalam perspektif hukum, melainkan sebagai peradaban yang mempengaruhi perkembangan pendidikan.

Terdapat beberapa penelitian berkaitan dengan arsitektur. Pertama, hasil penelitian Muhamad Ratodi dan Oktavi Elok Hapsari, seni arsitektur Islam memiliki enam karakteristik mendasar. Pertama, sebagai manifestasi keimanan dan ketauhidan. Kedua, gambaran surga dunia dan kemajuan peradaban Islam. Ketiga, bentuk pengakuan pada keagungan Sang Pencipta yang diwujudkan secara estetis dan keindahan. Keempat, pengakuan terhadap kebesaran Tuhan. Kelima, bentuk peribadatan kepada Allah dengan mengembangkan ilmu. Keenam, sebagai manifestasi dari ajaran Islam sendiri yang terwujud pada sebuah karya (Oktavi Elok Hapsari, 2017). Kedua, penelitian Aulia Fikriarini yang menyatakan bahwa seni arsitektur yang lahir dari representasi akhlaqi dan perilaku islami akan menghasilkan peradaban yang berbeda yang tidak dibatasi wilayah dan Negara. Bentuk antar arsitektur di dalam Islam tidaklah sama antara satu dengan lainnya, melainkan memiliki bahasa arsitektur yang berbeda tergantung kebermanfaatan dan fungsi dari suatu bangunan. Kekayaan arsitektur Islam merupakan bentuk bagi kekayaan khazanah dalam Islam yang bermuara pada rahmatan lil 'alamin (Fikriarini, 2010). Ketiga, hasil penelitian Yulia Eka Putrie dan Atik Hosiah yang mengemukakan bahwa ornament sebagai wujud peradaban tidaklah menyalahi nilai-nilai Islam. 
Keindahan dalam Islam sejatinya di dalamnya melekat nilai-nilai kebenaran dan ke Keindahan di dalam Islam tidak dapat dilepaskan dari nilai-nilai kebenaran dan kebaikan. Bukan hanya terletak pada keindahan, kemewahan saja, melainkan lebih menekankan aspek nilai(Putrie \& Hosiah, 2012) .

Adapun pengaruh seni arsitektur terhadap perkembangan pendidikan Islam di Andalusia merupakan penelitian literatur (library research) yang berusaha mengolah data yang berasal dari buku, jurnal, artikel maupun manuskrip terhadap objek pembahasan. Penelitian ini menggunakan metode penelitian sejarah dengan melakukan pengkajian, penjelasan, dan analisis kritis terhadap peninggalan masa lalu untuk dapat diperoleh informasi yang lebih komprehensif (Sjamsuddin, 2007). Penelitian ini menggunakan beberapa langkah. Pertama, heuristic, yaitu proses pengumpulan data yang mencakup kutipan atau seluruh dokumen, korespondensi, catatan dan catatan sejarah (Morissan, 2019). Kedua, kritis, dengan memilah dan memilih informasi yang valid dan data yang mendukung penelitian. Ketiga, Interpretatif, yaitu langkah penafsiran terhadap data, fakta dan kata-kata yang diperoleh. Keempat, historiografis yaitu penyusunan satu-kesatuan data, dan penafsiran yang dimanifestasikan dalam sebuah tulisan ilmiah.

\section{HASIL DAN PEMBAHASAN}

\section{Sejarah Perkembangan Andalusia}

Terbentuknya Andalusia tidak dapat terlepasakan dari sejarah panjang perkembangan Andalusia di bawah kekuasaan Bangsa Romawi, Visigotic dan Ummayah. Secara teoritis, nomenklatur Andalusia diambil dari berbagai istilah seperti Vandal (bangsa Jerman yang meninggali wilayah Andalusia), Arabisasi dari Antlantik dan (Landahlauts) yang dipahami oleh bangsa Visigothic dengan tanah undian (Rizem Aizid, 2017). Ditinjau dari perseptif sejarah, setidaknya terdapat dua gelombang bagi penaklukkan Andalusia. Pertama di bawah kekhalifahan Al-Walid bin Abdul Malik. Kedua, pada masa Kekahlifahan Umar bin Abdul 'Aziz (Syamruddin Nasution, 2018). Pada 
gelombang pertama, penaklukan Andalusia diiisiasi dengan penakhlukan wilayah-wilayah di Afrika Utara oleh 'Amr bin 'Ash pada tahun $21 \mathrm{H} / 642 \mathrm{M}$ dan 'Abdullah bin Abi Sarh pada tahun 27 H/647 M. Dalam penaklukan Andalusia, terdapat tiga tokoh sentral yang memiliki kontribusi bagi pembukaan gerbang Andalusia, yaitu Tarif bin Malik, Musa Bin Nusair, dan Tariq bin Ziyad.

Tharif merupakan perintis dan penyelidik yang pertama kali menyeberangi selat antara Maroko (al-Maghrib) dan benua Eropa dengan membawa 400 pasukan infantri dan 100 pasukan kavaleri sebagian besar pasukan adalah orang Berber, dengan menggunakan kapal perang bantuan dari Graft Julian penguasa legendaris Kristen yang menguasai Cueta. Dalam peperangan di bawah komando Tharif, mengalami kemenangan dan kembali ke Afrika Utara dengan membawa harta rampasan perang yang sangat banyak.

Musa Ibn Nusair sendiri merupakan Gubernur Afrika Utara mengutus Tariq bin Ziyad ke Spanyol tahun 711 M dengan membawa 7.000 orang pasukan yang mayoritas merupakan orang Berber. Dalam perjalanan menuju Spanyol Musa kembali mengirimkan 5.000 orang pasukan tambahan sehingga pasukan yang dipimpin oleh Tariq berjumlah 12.000 orang. Jumlah ini masih lebih sedikit dan tidak sebanding dari jumlah pasukan kerajaan Gothik yang berjumlah 100.000 orang. Tariq bersama pasukannya berhasil menyeberangi selat Gibraltar (Jabal Tariq) pada bulan Rajab 92 H. Pertempuran antara pasukan Tariq melawan pasukan Roderick di tepi sungai Barbate (Wadi Bakkah) pada 28 Ramadhan 92 H/19 Juli 711 M. Berkat kegigihan dan kesabaran Tariq dan pasukanya akhirnya pertempuran tersebut dapat dimenangkan. Setelah kemenangan itu, pasukan muslim dapat menguasai beberapa kota di Spanyol, di antaranya Ecija, Toledo (ibu kota kerajaan Gothik), Arkidona, Elvira, Kordova, dan Malaga (Hasan Ibrahim Hasan, 2003) . 
Setelah Thariq bin Ziyad mengalami kemenangan, Musa bin Nusair Gubernur Afrika Utara memutuskan untuk berangkat ke Spanyol dengan membawa pasukan berjumlah 10.000 orang tentara. Sama halnya yang dialami oleh Tariq, Musa dan pasukanya meraih kemenangan sehingga dapat menguasai Medina Sidonia, Carmona, Alcala de Guadaira, Seville, Merida, Saragosa, Aragon, Leon, Asturia, dan Galicia. Dilihat dari beberapa penaklukan yang dilakukan kaum muslimin sebenarnya tidak terlalu mengalami banyak kesulitan. Bahkan bisa dibilang mudah, hal ini dipengaruhi oleh beberapa faktor, baik faktor politik, sosial ekonomi, dan agama.

Adapun pada gelombang kedua, proses penaklukkan dikonsentrasikan di wilayah pegunungan Pyrenia dan Prancis selatan. Dibawah Pimpinan AlSamah, Pasukan Islam mengalami kegagalan. Begitu pula dibawah pimpinan Abdurrahman bin Abdullah, umat Islam gagal menaklukkan Perancis sehingga seluruh pasukan di tarik ke Spanyol. Kemajuan Andalusia sesungguhnya baru terlihat pada periode Abdurrahman Ad-Dakhil. Dengan memperbaiki stabilitas politik, mempersatukan heterogensi suku, dan membangun Cordova sebagai pusat peradaban, pengetahuan dan budaya, Andalusia menjadi mercusuar bagi Eropa.

Selama lebih dari tujuh abad, benturan positif peradaban Islam, Persia, India, Babilonia, Syiria dan Yunani melahirkan keilmuan baru bagi Andalusia (Mehdi Nakosteen, 2003). Dalam bidang Infrastruktur, dibangunlah beberapa istana seperti Ja'fariyah, Al-Makmun dan Al-Hamra'. Selain itu, pemerintah juga membangun fasilitas umum seperti jembatan, jalan, rumah, sarana ibadah dan perpustakaan. Untuk mengembangkan taraf hidup dan perekonomian Negara dibangunlah kanal, saluran irigasi dengan sistem hidrolik untuk meningkatkan hasil pertanian. Pada masa ini pula dikembangkan dunia industri dalam berbagai bidang seperti logam, tembikar,tekstil, kulit, kayu, kilang minyak, tepung, gelas bahkan barud (senjata pistol) (Asy'ari, 2018). 
Adapun dalam bidang ilmu pengetahuan dan teknologi, Andalusia melahirkan ulama, filosof, ahli bahasa, dokter, saintifik, maupun seniman. Dalam bidang ilmu naqli, lahirlah ulama sekaliber Ziyad bin Abdurrahman, Ibnu Yahya dan Ibu Hazm (Syed Mahmudunnasir, 1988). Dalam bidang filsafat, lahirlah tokoh sekaliber Ibnu Bajjah, Ibnu Masarrah, Ibnu Thufai dan Ibnu Rusyd di mana pemikiran mereka menginisiasi bagi kebangkitan Eropa. Dalam bidang kedokteran terdapat Ibnu Ja'far al-Ghafiqi dengan kitan AlAdawiyat Al-Mufrodah, Ibnu Khatima dokter ahli penyakit pademik, Abu Marwan bin Zuhr, dan Qashim Zahrawi dokter ahli bedah dengan kitab atTasrif liman 'Ajiza 'ani Taklif (Abdullah, 2018).

Kemajuan bidang sains ditandai dengan saintifik dalam bidang ilmu eksakta seperti matematika, kimia, astronomi, dan geografi. Terdapat beberapa ilmuan seperti Abbas bin Firnas (ahli ilmu kimia dan astronomi) (Suyuthi Pulungan, 2019), Al-Zarqali dengan astrolabe yang berfungsi untuk mengukur jarak horizon bumi dengan bintang, Jabir bin Aflah dengan al Hai'abnya dalam perkembangan ilmu ukur sudut bidang datar dan lingkaran (Faisal Ismail, 2017) dan Maslamah al-Majriti sang korektor astronomi Khwawrizmi. Selain itu, lahir pula ilmuan dalam bidang sejarah, bahasa, maupun seni. Dalam bidang sejarah terdapat akademisi sekelas Ibnu Khatib, Ibnu Khaldun, Ibnu Qutyah, Ibnu Hayyan, dan Abu Walid bin Abdullah AlFaradh (Rizem Aizid, 2017). Adapun tokoh yang berjasa dalam pengembangan bahasa dan satra adalah Ibnu Malik, Az-Zubaidi, Ibnu Hajj, Ibnu Sayyidah, dan Al-Qalidan. Sedangkan tokoh seni musik terdapat Hasan bin Nafi' (Ziryab).

\section{Seni Arsitektur Andalusia Dan Pengaruhnya Terhadap Pendidikan} Islam

Secara umum, istilah seni dapat didefinisikan dengan kegiatan hasil karya dalam masyarakat yang sering dipengaruhi oleh budaya, kepercayaan, kerajinan, makanan, pakaian dan sebagainya, yang tidak selalu memenuhi 
persyaratan estetis yang terdapat pada bidang seni sastra, seni musik dan seni arsitektur. Dalam Islam, seni merupakan manifestasi keindahan yang bermuara pada nilai tauhid sebagai esensi aqidah, tata nilai dan norma (Nanang, 2012).

Adapun Arsitektur dipandang dari kajian seni atau ilmu bangunan adalah seni yang muncul dari pola pikir seseorang kemudian dituangkan dalam bentuk bangunan. Arsitektur merupakan seni bangunan baik termanifestasi dalam bentuk maupun ragam hias (Gunawan, D. E., \& Prijadi, 2011). Istilah arsitektur Islam sesungguhnya merupakan karya arsitektur yang berlandaskan pendekatan konsep arsitektur Islam. meskipun demikian tidak menutup kemungkinan adanya akulturasi antara peradaban Islam dengan yang lainnya (Sutrisno et al., 2013). Sebagaimana disampaikan Wanita Subadra Abioso, meskipun arsitektur Islam dibangun oleh orang Islam, berada di wilayah teritori Islam dan dibawah pemerintahan Islam, akan substansi utamanya adalah kebermanfaatan bagi manusia rahmatan lil 'alamin.

Beberapa warisan seni arsitektur banyak ditinggalkan Dinasti Umayyah II di berbagai daerah seperti Cordoba, Granada, Sevilla dan Toledo. Terdapat berbagai seni arsitektur pada masa tersebut seperti masjid, istana, kota, pemukiman. Selain itu hampir setiap daerah dibangun jalan, pasar, jembatan, saluran, irigasi, tempat pemandian dan pabrik (Nur Dinah Fauziah, 2016). Beberapa bangunan seperti istana Al-Hamra, Ja'fariyyah,, Alcazar, masjid Cordova, masjid Seville, Madina Zahra, tembok Toledo dan Jembatan Cordoba menjadi saksi bagi perkembangan arsitektur Islam di Andalusia.

Ciri khas berbagai bangunan tersebut tidak dapat terlepas dari tiga hal: kaligrafi, bunga, dan geometri. Arsitektur di Andalusia, sesungguhnya bukan hanya menampilkan sebuah keindahan dari arsitektur, melainkan disadari ataupun tidak mengandung unsur sustainability dimana unsur air, dekorasi, konstruksi dan teknik material memiliki fungsi bagi bermanfaatan manusia. 
bahkan unsur sustainability berlaku dalam berbagai unsur religious seperti masjid, lembaga pendidikan, pesantren, benteng dan makam.

Istana Al-Hambra' di Granada merupakan salah satu manifestasi kemajuan seni arsitektur Islam.. Dengan dilengkapi berbagai ornament hiasannya stalaktit, mozaik, dan kaligrafi, istana Al-Hamra' merupakan representasi aristektur yang megah dan luas. Interior istana dilengkapi dengan kaligrafi yang sangat indah dan di tengahnya terdapat patung singa yang terbuat dari porselen. Al-Hamra' merupakan representasi taman surga court (patio, rbiad) yang terdiri dari beberapa bagian seperti kolam ikan yang dikelilingi taman bunga, kanal air, pemandian raja, menara ceremonial hall yang lantai dasarnya difungsikan untuk menjamu tamu, arcade arsitektur Moor, masjid dan taman (Joyce M. Laurens \& Esterlita Devi Hendrayani, 2002). Pembangunan Istana Al-Hamra sendiri didasarkan pada ilmu mekanik. dan ilmu geometri baik dalam denah, layout, fasade dan ornamen (Andi Pramono, 2012).

Sementara itu, peninggalan lainnya adalah Istana Alcazar di Sevilla, dengan selain memiliki tata ruang yang sangat rapi, ornamen dan dekorasi yang sangat megah yang menggambarkan kemajuan Andalusia sebagai mercusuar Eropa. Bagian paling tua dari istana Alcarez dibangun oleh arsitek Toledo atas perintah gubernur Muwahhidun pada 1199-1209. Istana ini direstorasi dengan gaya Islam oleh pekerja Mudejar untuk Raja Peter pasca runtuhnya kekuasaan di Islam di Andalusia dan dijadikan istana bagi para bangsawan.

Corak seni arsitektur Andalusia adalah corak Yunani atau Romawi, namun bangunan di Andalusia bukan tiruan dari negeri-negeri wilayah ke seni bangunan Romawi, bukan pula kekuasaan silam pada masa klasik, menurut bentuk seni bangunan Gotelah. Motif atau corak yang paling menonjol atau ciri khas dari seni arsitek di Andalusia adalah pada bentuk geometri kesenian arsitektur islam. Hal ini dapat dilihat pada bangunan yang memiliki sejarah di 
kota Granada, Andalusia, Alhambra yang terletak di Spanyol. Pola pembuatan denah, fasade dan ornamen yang menghiasi bangunan mengikuti rangkaian susunan matematik yang cukup sederhana dalam penataannya.

Dalam bidang arsitektur keindahan Spanyol bahkan menyaingi Konstantinopel, salah satu peninggalan Islam Spanyol antara lain : Al-Qashr al-Kabir, Medina al-Zahra di pegunungan Sierra Monera, Tembok Toledo, Masjid Jami' Cordova, Rushafat di Barat Laut Cordova, Istana al-Hambra di Granada, Masjid Seville dan masih banyak peninggalan bersejarah lainnya. Satu ciri yang spesifik dari arsitekturnya adalah banyaknya kolam dan tempat konservasi air dengan sumber air dari pegunungan dialirkan melalui saluran air yang panjangnya mencapai sekitar $80 \mathrm{~km}$ (Susanti, 2016).

Berbagai pengaruh peradaban Islam yang hingga kini masih ada adalah seni arsitektur Islam yang tertinggal pada berbagai bangunan yang ditinggalkan Bani Umayyah II di Andalusia. Peninggalan arsitektur tersebut tidak terlepas dari pengaruh kebudayaan Islam yang merupakan hasil akulturasi, asimilasi, atau inovasi berupa kebudayaan Islam baru yang belum ada sebelumnya pada masa itu. Para arsitektur pada masa itu mengimplementasikan keindahan yang dideskripsikan pada ayat Al Qur'an (A. Pramono, 2010). Metafora keindahan surga digambarkan dengan sifatsifat seperti memiliki taman-taman, pepohonan nan hijau, buah-buahan, mata air yang mengalir, dan sungai-sungai yang mengalir. Hal ini terlihat dari polarisasi penataan taman yang terdapat pada bangunan Islam di Andalusia yang memiliki pola sama, yaitu penempatan air mancur, jalan taman, semak yang ditata menjadi pagar, dan menempatkan pohon buah-buahan sebagai ikon taman.

Andalusia juga mengenalkan sistem irigasi pada bangsa Eropa (Napitupulu, 2019). Motif yang tertinggal pada bangunan di berbagai tempat di Andalusia hingga sekarang masih menjadi pembelajaran bagi masyarakat dan wisatawan yang berkunjung. Meski sebagian dari mereka tidak bisa 
membaca bunyi potongan ayat tersebut, namun hal ini tetap berpengaruh bagi perkembangan Islam di Andalusia. Tidak sedikit dari masyarakat yang mengagumi kehebatan arsitek dan ilmuwan muslim yang pada masanya berhasil meninggalkan seni yang begitu indah.

Kemajuan arsitektur yang dibangun Andalusia sesungguhnya menggambarkan bahwa terdapat dukungan finansial, pengembangan pendidikan, dan kesadaran masyarakat akan urgensi mempelajari ilmu pengetahuan. Selain itu dukungan penguasa (interest patronase) terhadap pembangunan fasilitas dan sumber daya manusia akan menghasilkan penemuan-penemuan baru yang berbasis nilai-nilai agama. Arsitektur sesungguhnya lahir dan mempengaruhi pola pendidikan Islam yang dimanifestasikan secara konkrit dalam bentuk bangunan, dekorasi, taman, kaligrafi dan lain sebagainya.

\section{PENUTUP}

Peninggalan Islam yang hingga kini tersebar di wilayah Andalusia merupakan bukti kejayaan Islam. Meskipun kini wilayah Andalusia tidak lagi di bawah muslim, namun peninggalan dan pemerintahan Islam yang pernah berkuasa masih memberikan pengaruh yang kuat bagi Andalusia, khususnya di bidang seni dan budaya.

Corak arsitektur yang masih ada dengan ukiran potongan ayat-ayat AlQuran dan Hadits sebagai motifnya kini menjadi bahan pendidikan bagi masyarakat Eropa, khususnya Andalusia yang kini menjadi Spanyol. Secara tidak langsung masyarakat mengetahui keindahan yang ditinggalkan oleh kejayaan Islam. Meski masyarakat tidak mengetahui arti dari motif tersebut, namun motif-motif tersebut akan memberikan kesan indah yang meninggalkan rasa penasaran pada Islam.

\section{DAFTAR REFERENSI}

Abdul Syukur Al-Azizi. (2017). Sejarah Terlengkap Peradaban Islam. Yogyakarta: Noktah. 
Abdullah, S. (2018). "Pembudayaan Ilmu Di Andalusia Dan Iktibarnya Untuk Pembangunan Tamadun di Malaysia ". Jumal PERADABAN, 11(1), 123. https://doi.org/10.22452/peradaban.vol11no1.1

Abu Muhammad Iqbal. (2015). Pemikiran Pendidikan Islam. Yogyakarta: Pustaka Pelajar.

Ahmad Syalabi. (2003). Sejarah dan Kebudayaan Islam. Jakarta: Pustaka Al Husna.

Asy'ari, H. (2018). Renaisans Eropa dan Transmisi Keilmuan Islam ke Eropa. JUSPI Jurnal Sejarah Peradaban Islam), 2(1), 1. https://doi.org/10.30829/j.v2i1.1792

Badri Yatim. (2006). Sejarah Peradaban Islam. Jakarta: Grafindo Persada.

Faisal Ismail. (2017). Sejarah dan Kebudayaan Islam Periode Klasik (Abad VIIXIII M. Yogyakarta: IRCiSoD.

Fikriarini, A. (2010). Arsitektur Islam: Seni Ruang dalam Peradaban Islam ((Islamic Architecture: Space Art in Islamic Civilization). El-Harakah, 12(3), 194-206.

Gunawan, D. E., \& Prijadi, R. (2011). Reaktualisasi Ragam ART DECO dalam Arsitektur Kontemporer. Media Matrasain, 8(1), 68-81.

Hasan Ibrahim Hasan. (2003). Sejarah dan Kebudayaan Islam 2. Jakarta: Kalam Mulia.

Ichsan, Y. (2020). Kontribusi Peradaban Andalusia terhadap Barat dan Kontekstualisasi Bagi Pendidikan Islam Masa Kini. At-Taqaddum, 12(2), 113-134.

Joyce M. Laurens, \& Esterlita Devi Hendrayani. (2002). Air Sebagai Subyek dalam Desain Arsitektur Kasus telaah: Istana Alhambra Granada. DIMENSI (Jurnal Teknik Arsitektur), 30(2), 102-109. Retrieved from http://puslit2.petra.ac.id/ejournal/index.php/ars/article/view/15771

Mehdi Nakosteen. (2003). Kontribusi Islam atas Dunia Intelektual Barat. Surabaya: Risalah Gusti.

Morissan. (2019). Riset Kualitatif. Jakarta: Kencana.

Nanang, R. (2012). Kedudukan Seni dalam Islam. Saqafa: Jurnal Kajian Seni Budaya Islam, 1(1), 1-8.

Napitupulu, D. S. (2019). Romantika Sejarah Kejayaan Islam di Spanyol. MUKADIMAH: Jurnal Pendidikan, Sejarah Dan Ilmu-Imu Sosial, 3(1), 7 18.

Nur Dinah Fauziah, M. M. M. Z. (2016). Peradaban Islam di Andalusia (Spanyol). AL-'AD ALAH: Jumal Syariah Dan Hukum Islam, 1(1), 80-91.

Oktavi Elok Hapsari, M. R. (2017). Identifikasi Best Practice Design Berdasar Hadits Sebagai Panduan. Nature, 4.

Pramono, A. (2010). Implementasi Al-Qur'an dan Al Hadits pada Arsitektur Andalusia. Journal of Islamic Architecture, 1(1), 21-26.

Pramono, Andi. (2012). Pola Geometri Pada Seni Dan Arsitektur Islam Di Andalusia. Journal of Islamic Architecture, 1(3), 133-136. 
https://doi.org/10.18860/jia.v1i3.1772

Putrie, Y. E., \& Hosiah, A. (2012). Keindahan dan ornamentasi dalam perspektif arsitektur islam. Journal of Islamic Architecture, 2(1).

Raghib As-Sirjani. (2012). Sumbangan Peradaban Islam Pada Dunia. Jakarta: Pustaka Al Kautsar.

Ramayulis. (2011). Sejarah Pendidikan Islam Napaktilas Perubahan Konsep, Filsafat dan Metodologi Pendidikan Islam Dari Era Nabi SAW sampai Ulama Nusantara. Jakarta: Kalam Mulia.

Rizem Aizid. (2017). Pesona Baghdad dan Andalusia: Meneropong Masa Kejayaan Islam Di Baghdad dan Andalusia. Yogyakarta: Diva Press.

Salleh, M. I., Wafi, M., Azman, N., Ihwani, S. S., Intelektual, M. Z. M. T., Pengaruh, A., \& Unisiti, D. A. (2018). Kemrujudan Sains dan Teknologi di Andalusia Mohd Iszatul Salleh, Mubd Wafi Nazrin Azman, \& Siti Subaila Ibwani. (April 2012).

Sjamsuddin, H. (2007). Metodologi Sejarah. Yogyakarta: Ombak.

Sumirah, Y. I. dan. (2020). Urgensi Olahraga dalam Perspektif Agama dan Aktualisasinya di Masa Pandemi Covid-19. Yazida. Jurnal Olahraga Indragiri, 7(2), 202-217.

Susanti, L. (2016). Mengupas Kejayaan Islam Spanyol dan Kontribusinya Terhadap Eropa. Jurnal RIS ALAH, 27(2), 57-61.

Sutrisno, A. F., Prijadi, R., Prodi, M., Arsitektur, S., Teknik, F., Ratulangi, U. S., ... Ratulangi, U. S. (2013). Karakteristik Arsitektur Menara Masjid Sebagai Simbol Islam Dari Masa Ke Masa. Media Matrasain, 10(2), 10 19.

Suyuthi Pulungan. (2019). Sejarah Pendidikan Islam. Jakarta: Prenada Media Group.

Syamruddin Nasution. (2018). Sejarah Peradaban Islam. Jakarta: PT Raja Grafindo Persada.

Syed Mahmudunnasir. (1988). Islam Konsepsi dan Sejarahnya. Bandung: Rosda Bandung. 